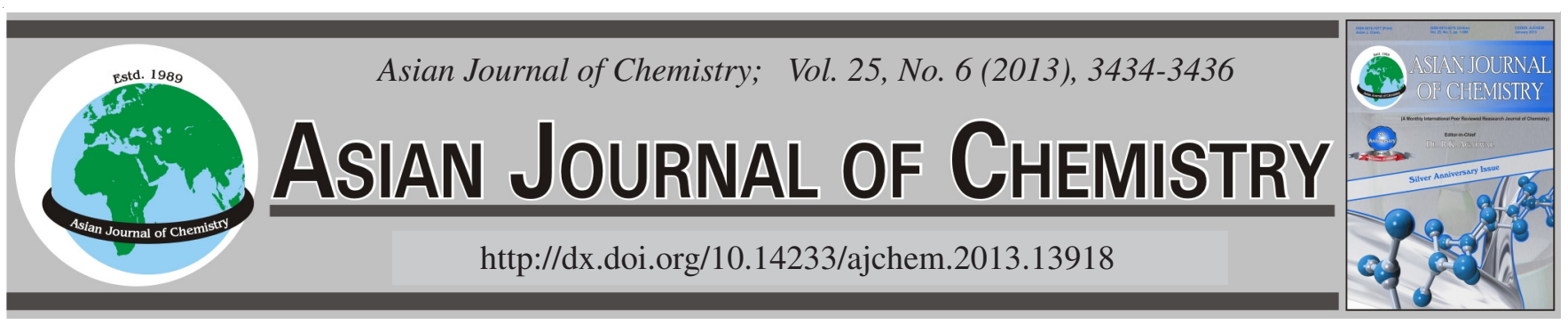

\title{
Assembly of 1D Cadmium(II) Coordination Polymer with Bis(2-benzimidazole) and 1,3-Benzenedicarboxylic Acid Mixed Ligands
}

\author{
Guo-Dong Feng ${ }^{*}$, Luan Jiang Xiao-Lin Luo and Min-Juan Wang
}

Key Laboratory of Functional Coordination Compounds, Department of Chemistry and Chemical Engineering, Baoji University of Arts and Science, No. 1 Hi-Tech Avenue, Baoji 721013, Shaanxi Province, P.R. China

*Corresponding author: Tel: +86 917 3566589; E-mail: fengguodong00805@163.com

\begin{abstract}
A novel one-dimensional cadmium(II) compound: $\left\{\left[\mathrm{CdL}\left(\mathrm{H}_{2} \mathrm{C}_{2} \mathrm{EIm}\right)\left(\mathrm{H}_{2} \mathrm{O}\right)\right]\left(\mathrm{H}_{2} \mathrm{O}\right)_{2}\right\}$ n (1) with 1,3-benzene dicarboxylic acid $\left(\mathrm{H}_{2} \mathrm{~L}\right)$ and 2,2'-(1,2-ethanediyl)bis $\left(1 \mathrm{H}\right.$-benzimidazole) $\left(\mathrm{H}_{2} \mathrm{C}_{2} \mathrm{EIm}\right)$ has been synthesized by means of hydrothermal method and characterized by Xray single-crystal diffraction. The crystal belongs to the triclinic system triclinic, space group P-1 with a $=1.0189(5) \mathrm{nm}, \mathrm{b}=1.1204(5)$ $\mathrm{nm}, \mathrm{c}=1.2319(5) \mathrm{nm}, \alpha=115.824(5)^{\circ}, \beta=98.363(5)^{\circ}, \gamma=102.654(5)^{\circ}, \mathrm{V}=1.1878(9) \mathrm{nm}^{3}, \mathrm{Dc}=1.649 \mathrm{~g} \mathrm{~cm}^{-3}, \mathrm{Z}=2, \mathrm{~F}(000)=594$, Goof $=0.997, \mathrm{R} 1=0.0358, \mathrm{wR}_{2}=0.0881$. The compound 1 shows a novel one-dimensional (1D) chain structure along the $\mathrm{c}$ axis and further extended into a $1 \mathrm{D}$ double chain structure through $\pi-\pi$ packing interactions. The intermolecular hydrogen bonds contribute to the formation of the three-dimensional supramolecular architecture and stabilize the crystal structure.
\end{abstract}

Key Words: Cadmium(II) polymer, Crystal structure, bis-(1H-benzimidazole).

\section{INTRODUCTION}

Known metal-organic frameworks has been aroused more and more people's interests because of variety of intriguing architectures and topologies and their potential applications in microelectronics, non-linear optics and catalysis ${ }^{1-4}$. Many of metal-organic frameworks are constructed by assembly of metal ions with an appropriate organic ligand, especially a bridging ligand containing nitrogen, oxygen, or sulfur atoms ${ }^{5}$. Strong metal-ligand coordination bonds, weak hydrogen bonds and $\pi-\pi$ interactions have been a general protocol to afford multidimensional metal-organic supramolecular entities ${ }^{6,7}$. The bis(2-benzimidazoles) and some substituted bis(2-benzimidazolyl)alkanes containing $\mathrm{N}$-donors are widely used as the bridging ligand in the construction of metal-organic frameworks due to their suitable flexible skeletons and two bridging moieties, which can lead to various modes of connections with metal ions ${ }^{8,9}$. Indeed, mononuclear ${ }^{10}$, dinuclear ${ }^{11}$, a 1D chain structures $^{12}$ and 2D sheet ${ }^{13}$ made of bis(2-benzimidazole) ligands have been reported. Comparatively, The 1,3-benzene dicarboxylic acid $\left(\mathrm{H}_{2} \mathrm{~L}\right)$, as a family rigid organic $\mathrm{O}$-donors are especially interesting because of their rigidity and various coordination numbers to metal ions ${ }^{14}$ and their abilities to act as H-bond acceptors and donors to assemble various supramolecular structures ${ }^{15}$. Based on these studies, we report syntheses and crystal structure of a new coordination polymer
$\left\{\left[\mathrm{CdL}\left(\mathrm{H}_{2} \mathrm{C}_{2} \mathrm{EIm}\right)\left(\mathrm{H}_{2} \mathrm{O}\right)\right]\left(\mathrm{H}_{2} \mathrm{O}\right)_{2}\right\}_{\mathrm{n}}$ based on the mixed ligands of aromatic carboxylates, 1,3-benzenedicarboxylic acid $\left(\mathrm{H}_{2} \mathrm{~L}\right)$ and $\mathrm{N}$-donor ligands, 2,2'-(1,2-ethanediyl) bis(1H-benzimidazole) $\left(\mathrm{H}_{2} \mathrm{C}_{2} \mathrm{EIm}\right)$.

\section{EXPERIMENTAL}

All chemical reagents were of analytical grade and used without further purification. The $\mathrm{H}_{2} \mathrm{C}_{2}$ EIm ligand was prepared according to the reported method ${ }^{16}$. The emission/excitation spectra were recorded on a Varian cary eclipse spectrometer. The single-crystal structure of the compound $\mathbf{1}$ was determined on a Bruker APXII CCD diffractometer.

The compound $\left\{\left[\mathrm{CdL}\left(\mathrm{H}_{2} \mathrm{C}_{2} \mathrm{EIm}\right)\left(\mathrm{H}_{2} \mathrm{O}\right)\right]\left(\mathrm{H}_{2} \mathrm{O}\right)_{2}\right\} \mathrm{n}(\mathbf{1})$ was prepared by the mixture of $\mathrm{Cd}\left(\mathrm{NO}_{3}\right)_{2} \cdot 4 \mathrm{H}_{2} \mathrm{O}(0.154 \mathrm{~g}, 0.5 \mathrm{mmol})$, 2,2'-(1,2-ethanediyl)bis (1H-benzimidazole) $\left(\mathrm{H}_{2} \mathrm{C}_{2} \mathrm{EIm}\right)(0.106$ g, $0.5 \mathrm{mmol})$, 1,3-benzene dicarboxylic acid $\left(\mathrm{H}_{2} \mathrm{~L}\right)(0.083 \mathrm{~g}$, $0.5 \mathrm{mmol})$ and $\mathrm{H}_{2} \mathrm{O}(16 \mathrm{~mL})$ was heated at $160^{\circ} \mathrm{C}$ for 3 days in a $25 \mathrm{~mL}$ Teflon-lined stainless steel vessel under autogenous pressure. After the reaction mixture was slowly cooled down to room temperature, colourless block crystals were obtained. Yield: $75 \%$.

Structure determination: A colourless block single crystal of compound 1 with $0.42 \mathrm{~mm} \times 0.31 \mathrm{~mm} \times 0.21 \mathrm{~mm}$ was carefully selected under a polarizing microscope and were mounted on a glass fiber and used for X-ray diffraction analyses. Single crystal structure determination by X-ray diffraction 
measurements were performed using a Bruker APXII CCD diffractometer with graphite monochromated $\mathrm{MoK}_{\alpha}(\mathrm{k}=$ $0.71069 \AA)$ radiation in the range of $1.91 \leq \theta \leq 28.20^{\circ}(-11<=$ $\mathrm{h}<=13,-14<=\mathrm{k}<=13,-15<=1<=16)$ at $293 \mathrm{~K}$. Absorption corrections were applied using the multi-scan technique ${ }^{17}$. A total of 7295 reflections including 5288 unique ones were collected, of which 5288 with $\mathrm{I}>2 \sigma(\mathrm{I})$ were considered as observed and used in the succeeding refinements. The structure was solved by the direct method and refined by full-matrix least-square techniques on F2 using SHELXL-97 ${ }^{18}$. All of the non-hydrogen atoms were refined anisotropically ${ }^{19}$. The $\mathrm{H}$ atoms attached to $\mathrm{C}$ atoms were positioned geometrically, with Uiso values derived from Ueq values of the corresponding $\mathrm{C}$ atom. The final $\mathrm{R}=0.0358$ and $\mathrm{w}=0.0881, \mathrm{~S}=0.997,(\Delta \rho)$ $\max =0.600$ and $(\Delta \rho) \min =-0.777 \mathrm{e} / \AA^{3}$.

Crystallographic data for the structural analysis(es) have been deposited with the Cambridge Crystallographic Data Centre, CCDC No.: 838278 for the compound $\mathbf{1}$.

\section{RESULTS AND DISCUSSION}

The molecular structure, ORTEP drawing, 1D chain structure and the 2-D network of the compound $\mathbf{1}$ are illustrated in Scheme-I and Figs. 1-3, respectively. Selected bond distances and angles for the complex are shown in Table-1. The single crystal X-ray analysis shows that the asymmetrical unit of the compound 1 contains one $\mathrm{Cd}(\mathrm{II})$ ion, one $\mathrm{H}_{2} \mathrm{C}_{2}$ EIm ligand, one $\mathrm{H}_{2} \mathrm{~L}$ molecule. As shown in Fig. 1, the one $\mathrm{Cd}(\mathrm{II})$ sites show a distorted octahedral geometry, being connected by three $\mathrm{O}$ atoms from two $\mathrm{H}_{2} \mathrm{~L}$ ligands and one coordinated water molecule. The remaining two coordination sites are occupied by two $\mathrm{N}$ atoms from one $\mathrm{H}_{2} \mathrm{C}_{2}$ EIm ligand. The $\mathrm{Cd}-\mathrm{O}$ bond lengths are in the range 2.246(2)-2.518(3) $\AA$ and the $\mathrm{Cd}-\mathrm{N}$ bond lengths are in the range 2.219(3)-2.355(3) $\AA$. The Cd(II) atoms are bridged by $\mathrm{H}_{2} \mathrm{~L}$ ligand with an intramolecular $\mathrm{Cd}---\mathrm{Cd}$ distance of $10.189 \AA$. A number of cases were reported in which a proton transferred from a carboxylic acid to an amine to form some novel proton transfer compounds ${ }^{20}$. In the crystal structure, to balance the charge, the $\mathrm{H}_{2} \mathrm{~L}$ as a proton donor was transferred to the $\mathrm{N}$-ring atom of bis-benzimidazoles.

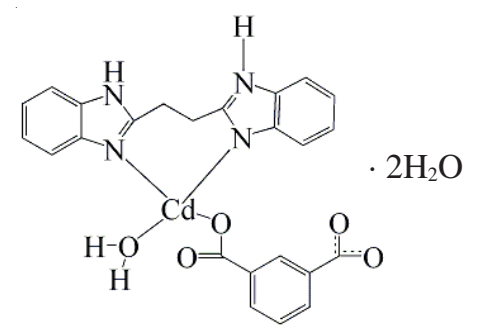

Scheme-I: Molecular structure of the compound $\mathbf{1}$

It is noticeable that $\mathrm{H}_{2} \mathrm{~L}$ anion in compound $\mathbf{1}$ shows two types of coordination modes with $\mathrm{Cd}$ ions through the carboxylate groups, as shown in Scheme-II, (i) The monodentate $\mathrm{H}_{2} \mathrm{~L}$ ligand links $\mathrm{Cd}$ atom with the carboxylate groups of the formyloxy. (ii) $\mathrm{The} \mathrm{H}_{2} \mathrm{~L}$ ligand coordinates adjacent cadmium atom, in which one carboxylate group containing $\mathrm{O}(3)$ and $\mathrm{O}(5)$ interacts with one $\mathrm{Cd}$ atom through a bidentate-chelating mode. Owning to the special coordination modes, each $\mathrm{H}_{2} \mathrm{~L}$

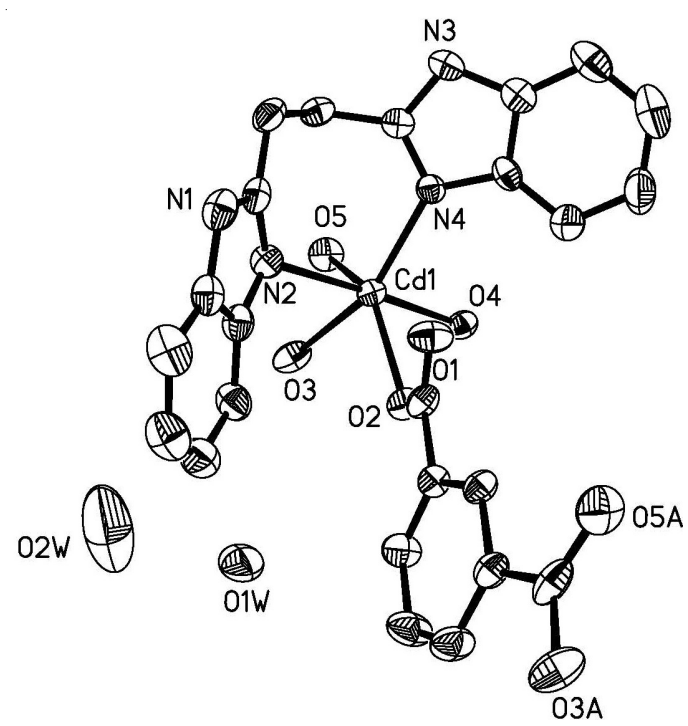

Fig. 1. Coordination environment of $\mathrm{Cd}(\mathrm{II})$ atom in compound (50\% thermal ellipsoids). Symmetry code: A: $-1+x, y, z$

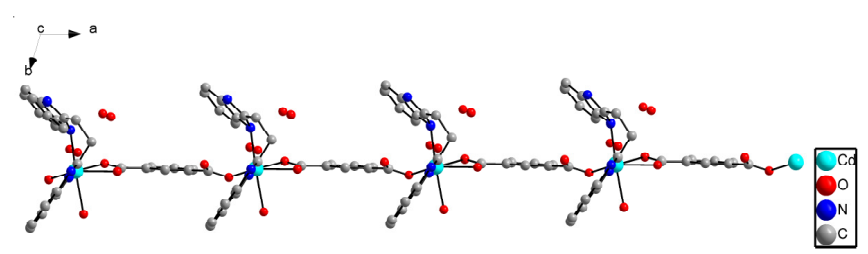

Fig. 2. Views of the $1 \mathrm{D}$ chain structure of compound $\mathbf{1}$ viewed down along the c-axis. Colour code: $\mathrm{Zn}$, teal; $\mathrm{C}$, gray; N, blue; O, red

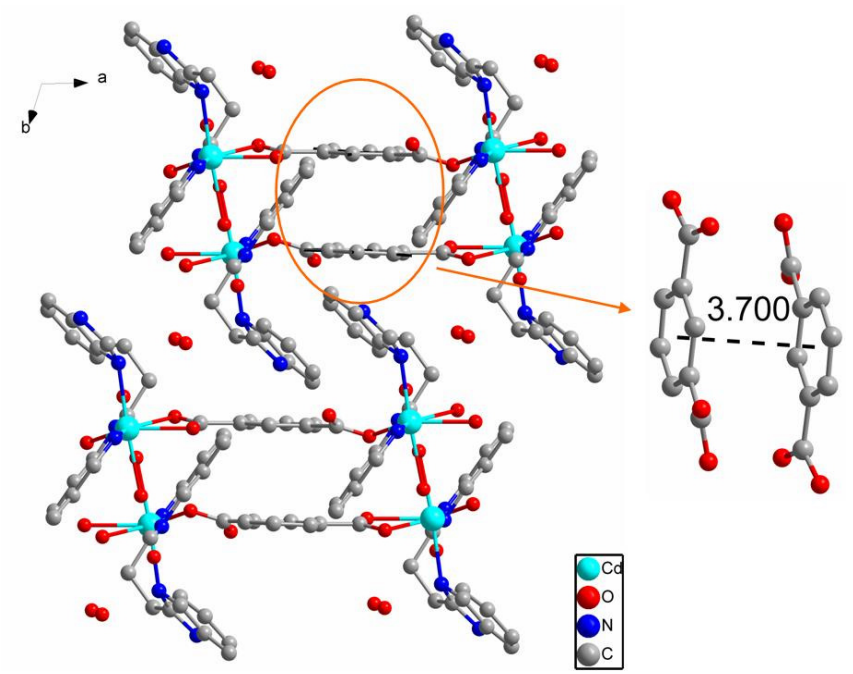

Fig. 3. View of the $2 \mathrm{D}$ double chain structure and the $\mathrm{p}-\mathrm{p}$ packing interaction in compound 1. Colour code: $\mathrm{Zn}$, teal; C, gray; N, blue; $\mathrm{O}$, red

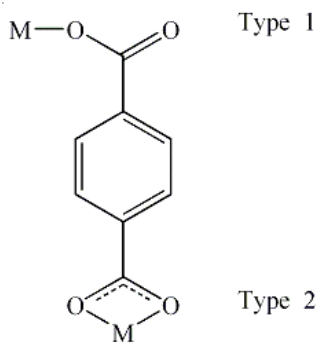

Scheme-II: The coordination modes of the $\mathrm{H}_{2} \mathrm{~L}$ with metals. Type 1 (monodentate), Type 2 (bidentate-chelating mode) 
anion acts as a $\mu_{2}$-bridge linking two $\mathrm{Cd}$ atoms into onedimensional (1D) chain structure along the $\mathrm{c}$ axis. By reason of the $\pi-\pi$ stacking interactions $\left(\mathrm{d}_{\text {face to face }}=3.700\right)$ among $\mathrm{H}_{2} \mathrm{C}_{2}$ EIm ligands, the $1 \mathrm{D}$ chain is linked to form a double chain network (Fig. 3.). Moreover, owning to the multiple nitrogen atoms in the $\mathrm{H}_{2} \mathrm{C}_{2}$ EIm ligand, hydrogen-bonding interactions are formed. As a result, the 1D double chain structure is further linked to form a three-dimentional network with the features a quasi-bedded structure by the intermolecular hydrogen bonds $\left(\mathrm{N}(3)-\mathrm{H}(111)-\mathrm{O}(1 \mathrm{~W})^{\mathrm{i}}=2.749(5), \mathrm{N}(1)-\mathrm{H}(222)-\mathrm{O}(1)^{\mathrm{ii}}=\right.$ 2.782(4), O(4)-H(66)-O(3) $)^{\mathrm{iii}}=2.723(4), \mathrm{O}(4)-\mathrm{H}(77)-\mathrm{O}(2)^{\mathrm{iv}}=$ 2.733(4), O(1W)-H(333)-O(2W $)^{\mathrm{v}}=2.771(11), \mathrm{i}=\mathrm{x}, \mathrm{y},-1+\mathrm{z}$, ii $=-\mathrm{x},-\mathrm{y},-\mathrm{z}, \mathrm{iii}=-\mathrm{x}, 1-\mathrm{y}, 1-\mathrm{z}, \mathrm{iv}=1-\mathrm{x}, 1-\mathrm{y}, 1-\mathrm{z}, \mathrm{v}=1-\mathrm{x},-\mathrm{y}, 1-\mathrm{z})$.

TABLE-1

SELECTED BOND LENGTHS $(\mathrm{nm})$ AND ANGLES $\left({ }^{\circ}\right)$

\begin{tabular}{lccc}
\hline \multicolumn{1}{c}{ Bond Length } & $\mathrm{nm}$ & \multicolumn{1}{c}{ Angles } & Degree \\
\hline $\mathrm{Cd}(1)-\mathrm{N}(4)$ & $2.219(3)$ & $\mathrm{N}(4)-\mathrm{Cd}(1)-\mathrm{O}(5)$ & $95.51(9)$ \\
$\mathrm{Cd}(1)-\mathrm{O}(2)$ & $2.246(2)$ & $\mathrm{O}(2)-\mathrm{Cd}(1)-\mathrm{O}(5)$ & $135.82(9)$ \\
$\mathrm{Cd}(1)-\mathrm{N}(2)$ & $2.355(3)$ & $\mathrm{N}(2)-\mathrm{Cd}(1)-\mathrm{O}(5)$ & $97.14(10)$ \\
$\mathrm{Cd}(1)-\mathrm{O}(5)$ & $2.358(3)$ & $\mathrm{N}(4)-\mathrm{Cd}(1)-\mathrm{O}(4)$ & $90.25(9)$ \\
$\mathrm{Cd}(1)-\mathrm{O}(4)$ & $2.462(3)$ & $\mathrm{O}(2)-\mathrm{Cd}(1)-\mathrm{O}(4)$ & $79.60(8)$ \\
$\mathrm{Cd}(1)-\mathrm{O}(3)$ & $2.518(3)$ & $\mathrm{N}(2)-\mathrm{Cd}(1)-\mathrm{O}(4)$ & $175.47(9)$ \\
$\mathrm{O}(1)-\mathrm{C}(23)$ & $1.240(4)$ & $\mathrm{O}(5)-\mathrm{Cd}(1)-\mathrm{O}(4)$ & $79.46(9)$ \\
$\mathrm{C}(24)-\mathrm{O}(5) \mathrm{i}$ & $1.236(5)$ & $\mathrm{N}(4)-\mathrm{Cd}(1)-\mathrm{O}(3)$ & $148.97(9)$ \\
$\mathrm{C}(24)-\mathrm{O}(3) \mathrm{i}$ & $1.274(4)$ & $\mathrm{O}(2)-\mathrm{Cd}(1)-\mathrm{O}(3)$ & $86.77(9)$ \\
$\mathrm{O}(1 \mathrm{~W})-\mathrm{H}(333)$ & 0.8756 & $\mathrm{~N}(2)-\mathrm{Cd}(1)-\mathrm{O}(3)$ & $88.92(10)$ \\
$\mathrm{N}(3)-\mathrm{H}(111)$ & 0.9136 & $\mathrm{O}(5)-\mathrm{Cd}(1)-\mathrm{O}(3)$ & $53.57(9)$ \\
$\mathrm{N}(1)-\mathrm{H}(222)$ & 0.9271 & $\mathrm{O}(4)-\mathrm{Cd}(1)-\mathrm{O}(3)$ & $86.64(9)$ \\
$\mathrm{O}(4)-\mathrm{H}(77)$ & 0.8274 & $\mathrm{~N}(4)-\mathrm{Cd}(1)-\mathrm{O}(2)$ & $123.00(9)$ \\
$\mathrm{O}(4)-\mathrm{H}(66)$ & 0.8171 & $\mathrm{~N}(4)-\mathrm{Cd}(1)-\mathrm{N}(2)$ & $93.07(10)$ \\
$\mathrm{O}(2)-\mathrm{C}(23)$ & $1.284(4)$ & $\mathrm{O}(2)-\mathrm{Cd}(1)-\mathrm{N}(2)$ & $101.10(9)$ \\
\hline Symmetry code: ${ }^{\mathrm{i}} \mathrm{x}-1, \mathrm{y}, \mathrm{z}$ & &
\end{tabular}

TABLE-2

DISTANCE (nm) AND ANGLES OF HYDROGEN -BONDING FOR COMPOUND

\begin{tabular}{lcccc}
\hline $\mathrm{D}-\mathrm{H}$ & $\mathrm{d}(\mathrm{D}-\mathrm{H})$ & $\mathrm{d}(\mathrm{H} . . \mathrm{A})$ & $<\mathrm{DHA}$ & $\mathrm{d}(\mathrm{D} . . \mathrm{A})$ \\
\hline $\mathrm{O}(4) \mathrm{H}(66) . . \mathrm{O}(3)^{\mathrm{i}}$ & 0.82 & 1.94 & 160 & $2.723(4)$ \\
$\mathrm{O}(4) \mathrm{H}(77) . . \mathrm{O}(2)^{\mathrm{ii}}$ & 0.83 & 1.98 & 151 & $2.733(4)$ \\
$\mathrm{N}(3)--\mathrm{H}(111) . . \mathrm{O}(1 \mathrm{~W})^{\mathrm{iii}}$ & 0.91 & 1.85 & 168 & $2.749(5)$ \\
$\mathrm{N}(1)--\mathrm{H}(222) . . \mathrm{O}(1)^{\mathrm{iv}}$ & 0.93 & 1.97 & 145 & $2.782(4)$ \\
$\mathrm{O}(1 \mathrm{~W})--\mathrm{H}(333) . \mathrm{O}(2 \mathrm{~W})^{\mathrm{v}}$ & 0.88 & 1.96 & 154 & $2.771(11)$ \\
\hline
\end{tabular}

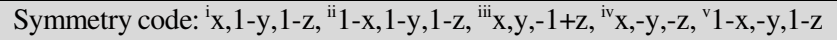

\section{Conclusion}

In summary, a novel one-dimensional (1D) cadmium(II) coordination polymer with the ligand $\left(\mathrm{H}_{2} \mathrm{C}_{2} \mathrm{EIm}\right)$ and aromatic ligand $\left(\mathrm{H}_{2} \mathrm{~L}\right)$ has been synthesized in hydrothermal reaction condition. Single crystal X-ray diffraction analyses revealed that the distorted octahedral $\mathrm{Cd}(\mathrm{II})$ centers are bridged by $\mathrm{H}_{2} \mathrm{C}_{2}$ EIm and $\mathrm{H}_{2} \mathrm{~L}$ ligands through the different coordination mode. It is found that the special coordination mode the plays a very important role in building the $1 \mathrm{D}$ chain structure along the $c$ axis. The successful syntheses of the compounds indicate that the $\pi-\pi$ packing interactions and the hydrogen-bonding interactions existing in the compound not only stabilize the crystal structure, but also confirm the significant potential of constructing high-dimentional network.

\section{ACKNOWLEDGEMENTS}

This work was financially supported by the research grant of Phytochemistry Key Laboratory of Shaanxi Province (No. 11JS006, 11JS007) and the Scientific Research Fund of shaanxi Provincial Education Department (No. 11JK0603).

\section{REFERENCES}

1. O.M. Yaghi, M. O'Keeffe, N.W. Ockwig, H.K. Chae and M. Eddaoudi, J. Kim. Nat., 423, 705 (2003).

2. A.J. Blake, N.R. Champness, P. Hubberstey, W.S. Li, M.A. Withersby and M. Schröder, Coord. Chem. Rev., 183, 117 (1999).

3. Y.-P. Hu, C.-P. Tan, S.-F. Wang and X.-B. Meng, Asian J. Chem., 25, 1137 (2013).

4. Z.Q. Jiang, Asian J. Chem., 25, 2353 (2013).

5. R. Wang, L. Han, F. Jiang, Y. Zhou, D. Yuan and M. Hong, Cryst. Growth Des., 5, 129 (2005).

6. (a) J.-M. Lehn, Supramolecular Chemistry: Concepts and Perspectives, VCH, Weinheim (1995); (b) J.W. Steed and J.L. Atwood, Supramolecular Chemistry, Wiley, New York (2000).

7. (a) J.C. MacDonald, P.C. Dorrestein, M.M. Pilley, M.M. Foote, J.L. Lundburg, R.W. Henning, A.J. Shultz and J.L. Manson, J. Am. Chem. Soc., 122, 11692 (2000); (b) J.C. Noveron, M.S. Lak, R.E. Del Sesto, A.M. Miller and P.J. Stang, J. Am. Chem. Soc., 124, 6613 (2002).

8. J.Y. Lu and V. Schauss, Inorg. Chem. Commun., 6, 1332 (2003).

9. Y.-B. Wang, X.-J. Zheng, W.-J. Zhuang and L. Jin, Eur. J. Inorg. Chem., 1355 (2003).

10. V. Arora, M. Gupta and P. Mathur, Indian J. Chem., 38, 1219 (1999).

11. G.A. van Albada, M.T. Lakin, N. Veldman, A.L. Spek and J. Reedijk, Inorg. Chem., 34, 4910 (1995).

12. G.A. van Albada, N. Veldman, A.L. Spek and J. Reedijk, J. Chem. Crystallogr., 30, 69 (2000).

13. L. Jiang, Z.X. Li and Z.M. Su, Inorg. Chem. Commun., 14, 1077 (2011).

14. V.A. Blatov, L. Carlucci, G. Ciani and D.M. Proserpio, Cryst. Eng. Comm., 6, 378 (2004).

15. M. Du, X.J. Jiang and X.J. Zhao, Inorg. Chem., 45, 3998 (2006).

16. L.Y.W. Lilian and M.J. Madeleine, J. Am. Chem. Soc., 79, 5706 (1957).

17. T. Higashi, Program for Absorption Correction, Rigaku Corporation, Tokyo, Japan, (1995).

18. SHELXTL, Version 5.1, Siemens Industrial Automation, Inc. (1997).

19. G.M. Sheldrick, SHELXL-97, Program for the Refinement of Crystal Structure, University of Göttingen, Germany (1997).

20. I.P. Santos and L.M.L. Marzan, Langmuir, 15, 948 (1999). 